\title{
PENGARUH EKONOMI MAKRO TERHADAP RETURN SAHAM JII DI BURSA EFEK INDONESIA
}

\author{
Windari \\ IAIN Padangsidimpuan \\ Jalan T. Rizal Nurdin Km. 4,5Sihitang, Padangsidimpuan \\ wwindariok@gmail.com
}

\begin{abstract}
ABSTRAK,
Penelitian ini mencoba mengkaji permasalahan apakah terdapat pengaruh ekonomi makro (inflasi, suku bunga Indonesia) terhadap Return saham JII secara di BEI. Data yang digunakan dalam penelitian ini adalah data sekunder dengan mempergunakan data gabungan time series (kurun waktu) dengan data Cross Section ( 8 perusahaan terpilih ) didasarkan pada laporan keuangan tahunan saham-saham yang tergabung dalam JII dari tahun 2013-2017. Hasil dari pengolahan data baik simultan dan parsial menunjukkan bahwa Ekonomi Makro (inflasi dan suku bunga Indonesia) berpengaruh terhadap return saham dengan tingkat signifikansinya dibawah 0,05.

Kata kunci :Return Saham, Inflasi dan SBI

\section{ABSTRACT,}

This study tries to examine the problem of whether there is macroeconomic influence (inflation, Indonesian interest rates) on JII stock returns on the IDX. The data used in this study is secondary data using combined time series data (time period) with Cross Section data (8 selected companies) based on the annual financial statements of shares that are incorporated in the JII from 2013-2017. The results of both simultaneous and partial data processing show that Macroeconomics (inflation and Indonesian interest rates) affect stock returns with a significance level below 0.05 .
\end{abstract}

Keywords: Stock Returns, Inflation and SBI 


\section{PENGARUH EKONOMI MAKRO TERHADAP RETURN SAHAM JII DI BURSA EFEK INDONESIA}

Windari

\section{PENDAHULUAN}

Transaksi di dalam pasar modal menurut syari'ah tidak dilarang (dibolehkan) sepanjang tidak terdapat transaksi yang bertentangan dengan ketentuan yang telah digariskan oleh syari'ah Islam. Hal ini disebabkan bahwa perkembangan ekonomi suatu negara tidak lepas dari perkembangan pasar modal. Dimana pasar modal berdasarkan prinsip syariah telah dikembangkan diberbagai negara. Oleh karena investasi di pasar modal tidak selalu sesuai dengan ketentuan syari'ah Islam, maka berinvestasi di pasar modal harus dilakukan dengan sangat selektif dan dengan sangat hati-hati, sehingga tidak masuk dalam investasi yang bertentangan dengan syari'ah (Habib, 2004).

Dalam melakukan investasi keperusahaan, pihak investor terlebih dahulu menganalisa suatu perusahaan tersebut dengan sejumlah informasi-informasi yang berkaitan dengan dinamika harga saham, yang didapat di pasar modal maupun yang didapatlangsungdariperusahaan. Hal tersebut dilakukan oleh investor untuk mengambil keputusan tentang saham perusahaan yang layak untuk dipilih. Investor yang menanamkan modalnya pada perusahaan tertentu sudah pasti mengharapkan return (keuntungan). Berinvestasi, semakin besar risiko suatu sekuritas, semakin besar return yang diharapkan. Sebaliknya juga semakin kecil return yang diharapkan, semakin kecil pula risiko yang harus ditanggung.

Sedangkan bila return saham dari suatu perusahaan dikatakan moderat, ini berarti return saham yang didapat investor tersebut tetap, hal ini berakibat investor yang ingin menanamkan modalnya tidak terlalu berambisi karena tidak ada kemajuan atau peningkatan. Bila return saham suatu perusahaan menurun akan berakibat investor akan mendapatkan hasil yang terus menurun akibatnya investor tidak mau menanamkan modalnya pada perusahaan tersebut.

Investor dalam menanamkan modalnya perlu untuk menganalisis tingkat kesehatan dan kinerja suatu perusahaan tersebut dengan mempertimbangkan ekonomi makro dalam strategi investasi yang akan dilakukan oleh investor. Ekonomi makro juga sangat penting diperhatikan dalam pengembalian saham, khususnya inflasi dan suku bunga Bank Indonesia. Naik turunnya suku bunga Bank Indonesia berpengaruh terhadap investasi. Hal itu disebabkan investor lebih memilih menanamkan modalnya di Bank dalam bentuk tabungan atau deposito, daripada melakukan investasi di bursa saham dengan tingkat resiko tertentu. Return dan risiko ini yang akan selalu melekat pada setiap investasi terutama investasi dalam setiap saham, baik saham biasa maupun saham yang sesuai dengan kaidah syariah.Berdasarkan uraian latar belakang penelitian diatas, penulis merumuskan permasalahan sebagai berikut :Apakah terdapat pengaruhekonomi makro (inflasi, suku bunga Bank Indonesia) terhadap Return saham JII di BEI? 
AT

J

JURNAL LMUUKOONOMIDAN KBISLAMAN
Al-Masharif: Jurnal Ilmu Ekonomi dan Keislaman

Volume 6 Nomor 1 Ed. Januari-Juni 2018 : hal. 117-129

p-ISSN: 2356-4628 e-ISSN : 2579-8650

\section{TINJAUAN TEORITIK}

\section{Return saham}

Return adalah tingkat kembalian yang dinikmati oleh pemodal atas suatu investasi yang dilakukannya. Tanpa adanya tingkat keuntungan yang dinikmati dari suatu investasi, tentunya investor (pemodal) tidak akan melakukan investasi. Jadi setiap investasi baik jangka pendek maupun jangka panjang mempunyai tujuan utama mendapatkan keuntungan yang disebut sebagai return baik langsung maupun tidak langsung (Ang, 1997).

Return merupakan hasil yang diperoleh dari investasi Return dapat berupa return realisasi yang sudah terjadi maupun return ekspektasi yang belum terjadi namun diharapkan akan terjadi di masa mendatang. Return realisasi merupakan return yang sudah terjadi. Return realisasi dihitung berdasarkan data historis. Return ini penting karena digunakan sebagai salah satu pengukur kinerja perusahaan dan juga berguna sebagai dasar penentuan return ekspektasi dan resiko di masadatang (Jugiono, 2003).

Return merupakan hasil yang diperoleh dari investasi yang berupa return realisasi (realized return) da nreturn ekspektasi (expected return) (Ade, 2008).

Return saham yang diperoleh dari kegiatan investasi yang berupa dividen bukanlah hal yang mudah untuk diprediksi, karena kebijakan dividen merupakan kebijakan yang sulit bagi manajemen perusahaan.

Keputusan mengenai dividen terkadang dikaitkan dengan keputusan pendanaan dan keputusan investasinya. Dividen setiap periodenya sesuai dengan fluktuasi dalam jumlah kesempatan investasi yang dapatditerima yang tersedia bagi perusahaan tersebut (Ade, 2008).

Return dibedakan menjadi dua: Return realisasi merupakan return yang telah terjadi yang berupa capital gain. Return ekspektasi merupakan return yang diharapkan akan diperoleh oleh investor di masa yang akan datang yang berupa Dividen (Jogiyanto, 2005).

Dalam Islam return sahamitu halal jika bertujuan untuk mempertemukan antara pengusaha yang memerlukan modal dengan investor yang kelebihan uang, sehingga sektor real bisa bangkit. Dengan cara ini, maka produksi, baik barang maupun jasa bisa meningkat untuk memenuhi kebutuhan masyarakat, serta membuka lapangan kerja bagi banyak orang dengan catatan tidak ada gharar (penipuan) atau riba yang mengurangi hak dan merugikan investor. Setelah itu, perusahaan berjalan dengan suntikan modal investor. Sesungguhnya kerjasama seperti ini (Mudharabah atau Musyarakah) yang kalau di zaman modern mungkin disebut dengan join venture sudah dikenal dan dihalalkan dalam Islam selama tidak ada tipu-menipu.

Dalam hadis yang diriwayatkan H.R. Abu Dawud, al-Daruquthni, al-hakim, dan alBaihaqi, Rasulullah Saw mengatakan: 


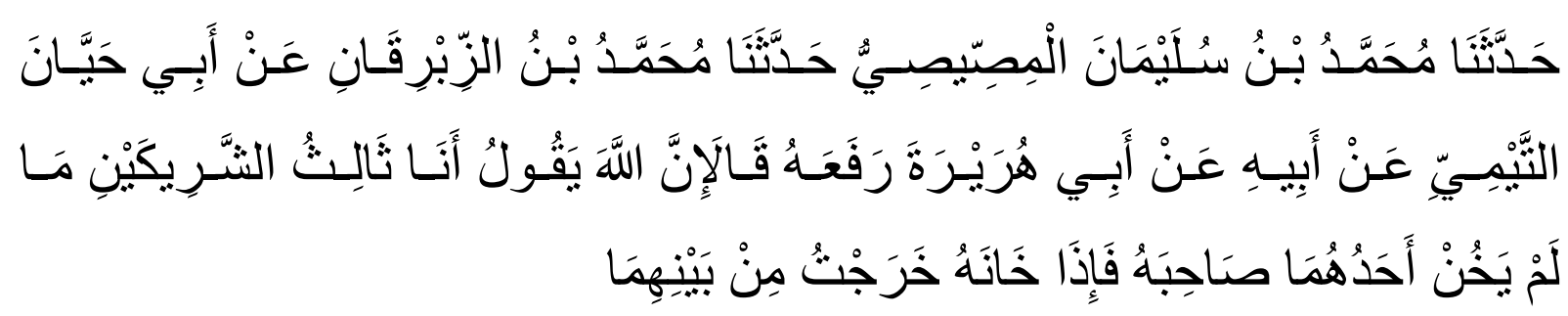

Artinya : "Saya adalah ketiga dari dua orang yang bersyarikat itu, selama salah satu pihak tidak mengkhianati kawannya, jika salah satu mengkhianati kawannya, maka saya akan keluar dari antara mereka berdua itu”. (Riwayat Abu Daud ) (Abu, 1990).

Hadis diatas menjelaskan dua orang yang saling bekerjasama pengusaha dan investor yang membuka lapangan kerja bagi banyak orang. Dari hasil kerjasama tersebut ada return (keuntungan) yang halal bagi investor jika kerjasama itu dilakukan dengan catatan tidak ada gharar (penipuan).

Sedangkan Alquran mengatakan dalam surat Al-Maidah ayat 2 berbunyi: Dalam ayat diatas Allah SWT menyerukan janganlah kamu umatnya untuk saling mengganggu orangorang yang mengunjungi Baitullah sedang mereka mencari kurnia dan keridhaan dari Tuhannya. Dimaksud dengan karunia ialah: Keuntungan yang diberikan Allah dalam perniagaan. Keridhaan dari Allah ialah: pahala amalan haji) dan saling tolong-menolonglah di dalam (mengerjakan) kebajikan dan takwa. Sama halnya dengan jual-beli saham di Bursa Saham (Stock Market) dimana hanya untuk mencari karunia dan saling tolong-menolong didalam pengembangan perusahaan tersebut.

\section{Ekonomi Makro}

Ekonomi makro merupakan bidang studi yang mempelajari perilaku perekonomian sebagai suatu kesatuan atau keseluruhan. Perhatiannya tercurah pada siklus-siklus usaha atau produksi, inflasi, pendapatan, harga serta berbagai kecenderungan jangka panjang dalam output dan standart hidup.

Analisis ekonomi makro adalah salah satu analisis yang perlu dilakukan investor dalam penentuan keputusan investasinya. Analisis ekonomi makro perlu dilakukan karena kecenderungan adanya hubungan yang kuat antara apa yang terjadi pada lingkungan ekonomi makro dengan kinerja suatu perusahaan dalam mewujudkan return saham. Banyak investor yang memusatkan perhatiannya pada suku bunga dan inflasi (Taddelilin, 2008).

Karena inflasi merupakan suatu indikator ekonomi makro yang menggambarkan kenaikan harga barang-barang dan jasa dalam suatu periode tertentu, dimana pengukurannya dapat menggunakan perubahan IndeksHarga Konsumen (IHK) sedangkan nilai tukar merupakan harga mata uang suatu negara yang dinyatakan dalam mata uang negara lainnya (J. Samuelson, 2001). 
Tingkat inflasi juga sangat berhubungan dengan jumlah uang yang beredar di masyarakat, untuk mengendalikan laju inflasi adalah dengan menaikkan tingkat suku bunga. Kebijakan menaikkan atau menurunkan tingkat suku bunga oleh Bank Indonesia ini dikenal dengan istilah politik diskonto yang merupakan salah satu instrumen dari kebijakan moneter.

\section{Inflasi}

Inflasi adalah kecenderungan dari harga-harga untuk meningkat secara umum dan terus menerus. Kenaikan harga dari satu atau dua barang saja tidak dapat disebut inflasi kecuali bila kenaikan itu meluas (atau mengakibatkan kenaikan) kepada barang lainnya. Kebalikan dari inflasi disebut deflasi.

Inflasi timbul karena adanya tekanan dari sisi supply, sisi permintaan, dan dari ekspektasi inflasi. Faktor terjadinya inflasi dapat disebabkan oleh depresiasi nilai tukar, dampak inflasi luar negeri terutama negara-negara partner dagang, peningkatan harga-harga komoditi yang diatur pemerintah, akibat bencana alam dan terganggunya distribusi (J. Samuelson, 2001).

Dalam konteks makro ekonomi, meningkatnya laju inflasi mengakibatkan menurunnya tingkat penjualan pada perusahaan-perusahaan publik sehingga laba yang mereka terima juga menurun. Sejak terjadinya krisis moneter yang kemudian diikuti oleh krisis ekonomi mengakibatkan kepercayaan masyarakat terhadap valuta domestik menurun. Padahal kepercayaan masyarakat terhadap valuta domestik merupakan kunci maju mundurnya ekonomi suatu negara, soalnya kepercayaan kepada mata uang dengan pelaksanaan pemerintahan atau kondisi politik memiliki hubungan yang saling mempengaruhi.

Seorang Trader akan selalu memperhatikan dengan seksama perkembangan tingkat inflasi. Salah satu cara pemerintah dalam menanggulangi inflasi adalah dengan melakukan kebijakan menaikkan tingkat suku bunga. Kebijakan peningkatan tingkat suku bunga ini diharapkan dapat memperkuat nilai tukar dan mengendalikan tingkat inflasi.

Penggunaan tingkat inflasi sebagai salah satu indikator fundamental ekonomi adalah untuk mencerminkan tingkat GDP dan GNP ke dalam nilai sebenarnya. Nilai GDP dan GNP merupakan indikator yang sangat penting bagi seorang Trader dalam membandingkan peluang dan resiko investasinya di luar negeri.

Beberapa indikator untuk mengetahui tingkat inflasiyaitu Producer Price Index (PPI), adalah indeks yang mengukur rata-rata perubahan harga yang diterima oleh produsen domestik untuk setiap output yang dihasilkan dalam setiap tingkat proses produksi. Data PPI dikumpulkan dari berbagai sektor ekonomi terutama dari sektor manufaktur, pertambangan 


\section{PENGARUH EKONOMI MAKRO TERHADAP RETURN SAHAM JII DI BURSA EFEK INDONESIA}

Windari

dan pertanian. Consumer Price Index (CPI), digunakan untuk mengukur rata-rata perubahan harga eceran dan sekelompok barang dan jasa tertentu.

Kedua indeks tersebut, CPI dan PPI, digunakan trader sebagai indikator untuk mengukur tingkat inflasi yang terjadi. Seorang trader tidak dapat berharap bahwa Bank Sentral akan menaikkan tingkat suku bunga apabila salah satu indikator memberikan sinyal kuat tentang adanya inflasi maupun menurunkan suku bunga untuk keadaan sebaliknya. Sebagai contoh, dampak Perang Teluk 1991 memicu naiknya harga minyak bumi sehingga indeks CPI di Amerika Serikat juga naik. Namun karena peningkatan indeks CPI itu tidak berlangsung lama, maka Bank Sentral Amerika Serikat tidak mengambil tindakan apapun.

Menurut para ekonomi Islam inflasi berakibat sangat buruk bagi perekonomian karena: (Karim, 2001). Menimbulkan gangguan terhadap fungsi uang, melemahkan semangat menabung masyarakat, meningkatkan kecenderungan untuk berbelanja terutama untuk non primer dan barang-barang mewah, mengarahkan inflasi pada hal-hal yang non produktif.

Inflasi sangat berakibat buruk bagi perekonomian karena pertama menimbulkan gangguan terhadap fungsi uang, terutama terhadap fungsi tabungan (nilai simpan), fungsi dari pembayaran dimuka, dan fungsi dari unit perhitungan. Kedua melemahkan semangat menabung dan sikap terhadap menabung dari masyarakat (turunnya marginal propensity to save). Ketiga meningkatkan kecenderungan untuk berbelanja terutama untuk non-primer dan barang-barang mewah. Keempat mengarahkan investasi pada hal-hal non produktif seperti penumpukan kekayaan seperti hanya tanah, bangunan, logam mulia, transportasi.

\section{Suku Bunga Bank Indonesia}

BI Rate adalah suku bunga kebijakan yang mencerminkan sikap atau stance kebijakan moneter yang ditetapkan oleh bank Indonesia dan diumumkan kepada publik. Fungsi dari BI Rate diumumkan oleh Dewan Gubernur Bank Indonesia setiap Rapat Dewan Gubernur bulanan dan diimplementasikan pada operasi moneter yang dilakukan Bank Indonesia melalui pengelolaan likuiditas (liquidity management) di pasar uang untuk mencapai sasaran operasional kebijakan moneter.

Sasaran operasional kebijakan moneter dicerminkan pada perkembangan suku bunga Pasar Uang Antar Bank Overnight (PUAB O/N). Pergerakan di suku bunga PUAB ini diharapkan akan diikuti oleh perkembangan di suku bunga deposito, dan pada gilirannya suku bunga kredit perbankan.

Dengan mempertimbangkan pula faktor-faktor lain dalam perekonomian, Bank Indonesia pada umumnya akan menaikkan BI Rate apabila inflasi ke depan diperkirakan melampaui sasaran yang telah ditetapkan, sebaliknya Bank Indonesia akan menurunkan BI Rate apabila inflasi ke depan diperkirakan berada di bawah sasaran yang telah ditetapkan (Karim, 2001). 
Dalam penjelasan Bank Sentral Indonesia dapat disimpulkan investor harus memperhatikan faktor suku bunga untuk mengetahui harapan hasil dari setiap investasi yang dilakukannya. Dengan adanya perubahan suku bunga, tingkat pengembalian hasil berbagai sarana invertasi akan mengalami perubahan, ada yang cenderung naik dan ada pula yang cenderung turun. Bunga yang tinggi ini tentunya akan berdampak pada alokasi dana investasi para investor. Investor produk bank seperti deposito atau tabungan jelas lebih kecil resikonya jika dibanding dengan investasi dalam bentuk saham. Karena investor akan menjual saham dan dananya akan ditempatkan di bank. Penjualan saham secara serentak ini akan berdampak pada penurunan harga saham secara signifikan.

\section{METODE PENELITIAN}

\section{Populasi dan Sampel}

Populasi adalah keseluruhan subjek penelitian (Suharsimi, 2002). Populasi dalam penelitian ini adalah saham-saham JII yang terdaftar di BEI selama periode 2013 - 2017. Dalam penentuan sampel peneliti menggunakan purposive sampling yaitu dengan cara menunjukkan langsung pada suatu populasi berdasarkan kriteria yang dimiliki sampel, dengan tujuan agar diperoleh sampel yang representatif sesuai dengan kriteria yang ditentukan.Sampel yang digunakan adalah berjumlah sampel 8 perusahaan.

\section{Model dan Teknik Analisis Data}

Model analisis yang digunakan dalam penelitian ini adalah regresi linier berganda. Dengan menggunakan program komputer eview untuk memperoleh hasil yang akurat dan tepat, serta pengolahan data dilakukan dengan cepat. Adapun uji yang dilakukan untuk penelitian ini adalah uji asumsi klasik, yaitu normalitas, autokorelasi, dan multikolinealiritas. Analisis regresi linier berganda yang dirumuskan sebagai berikut:

$$
\mathbf{T R}=\mathbf{a}+\mathbf{b 1 X 1}+\mathbf{b 2 X 2}+\mathbf{e i}
$$

Dimana :

$$
\begin{array}{ll}
\mathrm{TR} & =\text { Total Return Saham } \\
\mathrm{a} & =\text { Konstanta } \\
\mathrm{b} 1-\mathrm{b} 2 & =\text { KoefisienRegresi } \\
\mathrm{X} 1 \quad=\text { Inflasi } \\
\mathrm{X} 2 \quad=\text { Suku Bunga Bank Indonesia } \\
\mathrm{ei=} \text { Error }
\end{array}
$$




\section{HASIL PENELITIAN}

\section{Hasil Uji Model Penelitian}

Model penaksiran yang dipakaipada penelitian ini berdasarkan Model Regressi Data Panel: Fixed Effect Model (FEM) dengan cross-section weights karena menghasilkan hasil estimasi yang lebih baik dibandingkan FEM biasa.

\section{Tabel1. Hasil Taksiran Model Regressi Pooled -Cross-Section Weights}

Dependent Variable: RETURN?

Method: GLS (Cross Section Weights)

Date: 03/07/18 Time: 04:14

Sample: 20132017

Included observations: 5

Number of cross-sections used: 8

Total panel (balanced) observations: 40

Convergence achieved after 36 iterations

\begin{tabular}{crrrr}
\hline \hline Variable & Coefficient & Std. Error & t-Statistic & Prob. \\
\hline \hline INFLASI? & -0.236654 & 0.041941 & -5.642483 & 0.0000 \\
SBI? & 0.487922 & 0.063760 & 7.652445 & 0.0000 \\
Fixed Effects & & & & \\
_AT--C & -1.349174 & & & \\
_BR--C & -1.276950 & & & \\
_ITP--C & -2.264794 & & & \\
_IN--C & -1.603743 & & & \\
_KF--C & -1.414120 & & & \\
_TBB--C & -1.463375 & & & \\
_TI-C & -2.197427 & & & \\
_UI--C & -0.156845 & & & \\
\hline \hline
\end{tabular}

\begin{tabular}{lrlr}
\hline \hline Weighted Statistics & & & \\
\hline \hline R-squared & 0.914975 & Mean dependent var & 1.312440 \\
Adjusted R-squared & 0.872463 & S.D. dependent var & 2.173904 \\
S.E. of regression & 0.776352 & Sum squared resid & 15.67078 \\
F-statistic & 21.52257 & Durbin-Watson stat & 2.409170 \\
Prob(F-statistic) & 0.000000 & & \\
\hline \multicolumn{1}{c}{ Unweighted } & & & \\
\multicolumn{1}{c}{ Statistics } & & & \\
\hline \hline R-squared & 0.408258 & Mean dependent var & 0.69650 \\
& & & O \\
Adjusted R-squared & 0.112387 & S.D. dependent var & 0.82404 \\
& & & 1 \\
S.E. of regression & 0.776356 & Sum squared resid & 15.67094 \\
Durbin-Watson stat & 2.980019 & & \\
\hline \hline
\end{tabular}

Data diolahdenganEViews4,1 


\section{Pengujian Hipotesis}

Pengujian goodness of fit dilakukan untuk menentukan kelayakan suatu model regresi. Variabel penelitian yang digunakan pada penelitian ini lebih dari dua variabel maka kelayakan tersebut dapat dilihat dari nilai Adjusted $R$ Square. Nilai Adjusted $R$ Square yang diperoleh dari hasilpengolahan data dapat dilihat pada Tabel 2 di bawah ini :

Tabel 2 Pengujian Goodness of Fit

\begin{tabular}{|l|r|c|r|}
\hline R-squared & 0.914975 & Mean dependent var & 1.312440 \\
\hline Adjusted R-squared & 0.872463 & S.D. dependent var & 2.173904 \\
\hline S.E. of regression & 0.776352 & Sum squared resid & 15.67078 \\
\hline F-statistic & 21.52257 & $\begin{array}{c}\text { Durbin-Watson } \\
\text { stat }\end{array}$ & $\mathbf{2 . 4 0 9 1 7}$ \\
\hline Prob(F-statistic) & 0.000000 & & \\
\hline
\end{tabular}

Sumber :Hasil Olahan Eview

Nilai Adjusted $R$ Square pada Tabel 2 diatas sebesar 0,8724. Hal ini menunjukkan bahwa 87,24 \% variabel Return Saham dapat dijelaskan oleh Ekonomi Makro (inflasi, suku bunga indonesia) sedangkan sisanya sebesar 12,76 \% dipengaruhi oleh variabel lain yang tidak dijelaskan oleh model penelitian ini.

Untuk menguji apakah parameter koefesien Adjusted $R^{2}$ signifikan atau tidak maka dilakukan pengujian dengan bantuan alat uji statistik metode Fisher (Uji F) dengan tingkat keyakinan (confident level) sebesar $95 \%$. Kriteria pengujian yang digunakan adalah apabila $F_{\text {hitung }}>F_{\text {tabel }}$ maka Ho ditolak; dan apabila $F_{\text {hitung }} \leq F_{\text {tabel }}$ maka Ho dapat diterima.

Tabel 2 menunjukkan bahwa nilai $F_{\text {hitung }}$ adalah 21,52257 dengan tingkat signifikansi o,ooo. Sedangkan $\mathrm{F}_{\text {tabel }}$ pada tingkat kepercayaan $95 \%(\alpha=0,05)$ adalah 2,46. Oleh karena pada kedua perhitungan $\mathrm{F}$ hitung $>\mathrm{F}$ tabel $(21,52257>2,46)$. Hal ini menunjukkan bahwa terdapat pengaruh secara simultan variabel Ekonomi Makro (inflasi dan suku bunga indonesia) terhadap return saham dapat diterima secara keseluruhan.

Secara parsial tergambar dalam Tabel 3 berikut : 


\section{Tabel 3 Hasil Perhitungan Uji t}

Dependent Variable: RETURN?

Method: GLS (Cross Section Weights)

Date: 03/07/18 Time: 04:14

Sample: 20132017

Included observations: 5

Number of cross-sections used: 8

Total panel (balanced) observations: 40

Convergence achieved after 36 iterations

\begin{tabular}{crrrr}
\hline \hline Variable & Coefficient & Std. Error & t-Statistic & Prob. \\
\hline \hline INFLASI? & -0.236654 & 0.041941 & -5.642483 & 0.0000 \\
SBI? & 0.487922 & 0.063760 & 7.652445 & 0.0000 \\
Fixed Effects & & & & \\
_AT--C & -1.349174 & & & \\
_BR--C & -1.276950 & & & \\
_ITP--C & -2.264794 & & \\
_IN--C & -1.603743 & & \\
_KF--C & -1.414120 & & \\
_TBB--C & -1.463375 & & \\
_TI--C & -2.197427 & & \\
_UI--C & -0.156845 & & \\
\hline \hline Weighted Statistics & & & \\
\hline \hline R-squared & 0.914975 & Mean dependent var & 1.312440 \\
Adjusted R-squared & 0.872463 & S.D. dependent var & 2.173904 \\
S.E. of regression & 0.776352 & Sum squared resid & 15.67078 \\
F-statistic & 21.52257 & Durbin-Watson stat & 2.409170 \\
Prob(F-statistic) & 0.000000 & & \\
\hline \hline Unweighted Statistics & & & \\
\hline \hline R-squared & 0.408258 & Mean dependent var & 0.69650 \\
& & & \\
Adjusted R-squared & 0.112387 & S.D. dependent var & 0.82404 \\
& & & 15.67094 \\
S.E. of regression & 0.776356 & Sum squared resid & \\
Durbin-Watson stat & 2.980019 & & \\
\hline \hline
\end{tabular}

Sumber: Output Evies.

Setelah melakukan pengujian diatas dapat disimpulkan bahwa model yang diajukan di dalam penelitian ini yang diuji dengan metode regresi berganda dengan metode fixed effect, Pengujian ini untuk melihat signifikansi model serta tingkat pengaruh antara variabel yang diteliti. Pengujian model ini digunakan untuk menguji hipotesis yang diajukan di dalam penelitian. Dari tabel coefficient perhitungan Uji t diatas maka model regresi yang dapat dibentuk : 
Substituted Coefficients:

$$
\begin{aligned}
& ================= \\
& \text { RETURN_AT }=-1.349173594-0.2366541516 * \text { INFLASI_AT }+0.4879222578 * \text { SBI_AT } \\
& \text { RETURN_BR }=-1.276949523-0.2366541516 * \text { INFLASI_BR }+0.4879222578^{*} \text { SBI_BR } \\
& \text { RETURN_ITP }=-2.264794046-0.2366541516 * \text { INFLASI_ITP }+0.4879222578^{*} \text { SBI_ITP } \\
& \text { RETURN_IN }=-1.603743233-0.2366541516 * \text { INFLASI_IN }+0.4879222578^{*} \text { SBI_IN } \\
& \text { RETURN_KF }=-1.414119522-0.2366541516 * \text { INFLASI_KF + 0.4879222578*SBI_KF } \\
& \text { RETURN_TBB }=-1.463374985-0.2366541516 * \text { INFLASI_TBB + 0.4879222578*SBI_TBB } \\
& \text { RETURN_TI }=-2.197427369-0.2366541516 * \text { INFLASI_TI + 0.4879222578*SBI_TI } \\
& \text { RETURN_UI }=-0.1568451658-0.2366541516 * \text { INFLASI_UI + 0.4879222578*SBI_UI }
\end{aligned}
$$

Hasil Perhitungan uji t tersebut menunjukkan secara parsial bahwa variabel Inflasi dan SBI yang tingkat signifikansi nya dibawah 0,05. Hasil pengujian hipotesis yang dilakukan secara parsial terhadap return saham adalah sebagai berikut :

Nilai konstanta untuk setiap perusahaan berbeda satu sama lain yang ditunjukkan oleh model fixed effect yaitu sebagai berikut :

Fixed Effects

\begin{tabular}{rr} 
_AT-C & -1.349174 \\
- $\mathrm{BR}-\mathrm{C}$ & -1.276950 \\
- $\mathrm{ITP}-\mathrm{C}$ & -2.264794 \\
_IN-C & -1.603743 \\
- $\mathrm{KF}-\mathrm{C}$ & -1.414120 \\
- $\mathrm{TBB}-\mathrm{C}$ & -1.463375 \\
- $\mathrm{TI}-\mathrm{C}$ & -2.197427 \\
_UI-C & -0.156845 \\
\hline
\end{tabular}

Hal ini menunjukkan apabila nilai INF , dan SBI bernilai nol, maka nilai return saham akan sebesar nilai -1.3 untuk AT; -1.2 untuk BR; -2,26 untuk ITP; -1,6 untuk IN; -1,5 untuk KF; -1,4 untuk TBB; -2.19 untuk TI dan -0,15 untuk UI. Koefisien regresi INF $\left(\mathrm{X}_{5}\right)$ sebesar -0,2366 memberikan pengertian bahwa perubahan INF sebanyak 1\% akan memberikan dampak sebesar -0,2366\% dengan arah yang berbeda. Koefisien regresi SBI $\left(\mathrm{X}_{6}\right)$ sebesar 0,4879 memberikan pengertian bahwa perubahan SBI sebanyak 1\% akan memberikan dampak sebesar 0,4879\% dengan arah yang sama. 


\section{PENGARUH EKONOMI MAKRO TERHADAP RETURN SAHAM JII DI BURSA EFEK INDONESIA}

Windari

\section{Pembahasan}

Pengujian yang dilakukan diatas terhadap model menunjukkan bahwa model yang diajukan secara signifikan membuktikan adanya pengaruh secara simultan Ekonomi Makro (inflasi, suku bunga indonesia) terhadap return saham. Pengaruh ini tidak terlalu besar jika ditinjau dari koefisien determinasi yang hanya berada di sekitar 87,23 \%. Hasil penelitian ini tidak sejalan dengan berbagai penelitian di pasar modal sebelumnya bahwa hubungan yang kuat antara analisis fundamental dan analisis teknikal dengan return saham tidak secara kuat dan nyata. Hal ini karena model yang dilakukan berbeda dan model dalam penelitian ini lebih baik dari hasil sebelumnya. Hasil yang diperoleh sering tidak konsisten sehingga tidak dapat ditarik kesimpulan yang jelas.

Hasil yang tidak konsisten ini merupakan indikasi bahwa memang tidak terdapat pola yang kuat terkait dengan masalah ini. Faktor penyebab yang sering diduga menjadi penyebab hal ini adalah masalah rentang waktu dari informasi akuntansi yang diumumkan telah terlebih dahulu diprediksi oleh investor. Keadaan tersebut menyebabkan efek dari informasi akuntansi sering bukan pada periode yang sama dengan return saham yang diambil sebagai data penelitian, sehingga penelitian yang dilakukan dengan memasangkan data pada interval waktu yang sama tidak dapat membuktikan hubungan yang signifikan. Secara parsial tidak ada satu variabel-pun yang menunjukkan bahwa terdapat variabel yang memberikan pengaruh positif return saham.

\section{KESIMPULAN}

Berdasarkan hasil analisis data serta pembahasan yang dilakukan pada bagian sebelumnya, maka penelitian ini menghasilkan beberapa kesimpulan sebagai berikut: saham-saham perusahaan yang tergolong di Jakarta Islamic Indeks merupakan perusahaan yang jenis, produk barang jasa yang diberikan dan akad serta cara pengelolaan tidak bertentangan dengan prinsip-prinsip Syariah. Demikian halnya mengenai bagi hasil, juga harus sesuai dengan Syariah, tidak adanya unsur bunga, karna bunga itu termasuk dalam riba, dan kegiatan yang mengandung unsur riba dilarang dalam pasar modal Syariah sesuai dengan keputusan fatwa Dewan Syariah Naional No: 40/DSN-MUI/X/2003.

Secara simultan variabel Ekonomi Makro (inflasi dan suku bunga Indonesia) terhadap return saham dapat diterima secara keseluruhan dimana nilai $\mathrm{F}_{\text {hitung }}$ adalah 21,52257, dengan tingkat signifikansi 0,00o. Sedangkan $\mathrm{F}_{\text {tabel }}$ pada tingkat kepercayaan $95 \%$ $(\alpha=0,05)$ adalah 2,34. Oleh karena pada kedua perhitungan $F$ hitung $>F$ tabel $(21,52257>$ 2.34), hal ini memberikan kesimpulan yang mendukung penelitian berbagai penelitian sebelumnya. 


\section{DAFTAR PUSTAKA}

Achsien, Inggi H, 2000,Investasi Syariah di Pasar Modal: Menggagas Konsep dan Praktek Manajemen Portofolio Syariah, Jakarta, Gramedia.

Alwi, Iskandar Z, 2003, Pasar Modal, Teori dan Aplikasi, Jakarta, Nasindo Internusa.

Darmaji, Tjiptono \& Fakhruddin, 2001, Pasar Modal Indonesia,, Jakarta, Salemba Empat.

Hamzah,Ardi, 2005, Analisa Karakteristik Perusahaan, Industri Dan Ekonomi Makro Terhadap Return Dan Beta Saham Syariah Di Bursa Efek Indonesia, Solo , Jurnal SNA-8.

Hamdan Junaldi, 2007, Analisis Pengaruh Faktor Fundamental Dan Kurs Valuta Asing Terhadap Return Saham Sektor Telekomunikasi Di Bursa Efek Jakarta Tahun 2003200, Universitas Islam Indonesia dipublikasikan,Universitas Islam Indonesia dipublikasikan.

Jogiyanto, 2003, Teori Portofolio dan Analisis Investasi Edisi 2, Yogyakarta : BPFE.

Kamaruddin, Ahmad, 2004, Dasar-dasar Manajemen Investasi dan Portopolio, Jakarta, Rineka Cipta.

Muda,Iskandar,Nasser, Abdul, Hasibuan, 2017, public discovery of the concept on money with the value of time, emersld reach proceeding series(proceeding of micoms, http://www.emeraldinsight.com/doi/pdfpluss/10.1108/978-1-78756-793-1-00050

Robert, Ang, 1997. BukuPintarPasar Modal Indonesia, Jakarta, Media Staff Indonesia.

Fatma Lubis, Ade, 2008, Pasar modal,Jakarta, FEUI.

Freddy Rangkuti, 2001, Teknik Membuat Perencanaan Bisnis dan Analisis Kasus, cetakan ketiga,Jakarta, Gramedia Pustaka Utama. 